\title{
Uterine Rupture in an Unscarred Uterus Following Induced Labor with Titrated Oral Misoprostol
}

\author{
William Ceurvels ${ }^{1}$, Shi-Yann Cheng ${ }^{2,3^{*}}$ \\ ${ }^{1}$ College of Chinese Medicine, China Medical University, Taiwan \\ ${ }^{2}$ School of Medicine, China Medical University, Taiwan \\ ${ }^{3}$ Department of Obstetrics and Gynecology, China Medical University Beigang Hospital, Taiwan \\ Email: "shiyann.cheng@msa.hinet.net
}

Received 24 July 2015; accepted 27 November 2015; published 30 November 2015

Copyright (C) 2015 by authors and Scientific Research Publishing Inc.

This work is licensed under the Creative Commons Attribution International License (CC BY). http://creativecommons.org/licenses/by/4.0/

(c) (i) Open Access

\begin{abstract}
Misoprostol (Cytotec, Pfizer) is a prostaglandin E1 analogue widely used in labor induction. Understanding of potential risks of misoprostol in labor induction is lacking as the drug is used off-label in most countries. A 35-year-old G3P2 woman with post-date pregnancy at $40+3$ weeks was induced using titrated oral misoprostol. Following delivery, post-partum hemorrhage was noted and, upon discovery of a uterine wall rupture due to congenital weakness of the myometrium, emergency abdominal total hysterectomy was conducted. Following surgery, the patient made a full recovery and was discharged. The main contraindications for misoprostol in labor induction are a scarred uterus or multipara greater than 4. Uterine wall weakness should be considered as a potential contraindication. Extreme vigilance is required in use of misoprostol for labor induction.
\end{abstract}

Keywords

Labor Induction, Misoprostol, Post-Partum Hemorrhage, Uterine Rupture

\section{Introduction}

Misoprostol, a potent uterotropic and uterotonic agent causing cervical effacement and dilation, and stimulating myometrial contraction, is commonly used in labor induction or augmentation [1] [2]. Because labor induction with titrated oral misoprostol solution is an effective and safe method according to our previous studies [3]-[6],

${ }^{*}$ Corresponding author.

How to cite this paper: Ceurvels, W. and Cheng, S.-Y. (2015) Uterine Rupture in an Unscarred Uterus Following Induced Labor with Titrated Oral Misoprostol. Open Journal of Obstetrics and Gynecology, 5, 795-798.

http://dx.doi.org/10.4236/ojog.2015.514112 
it has become the standard method used in our obstetric unit since 2004. This administration of hourly oral misoprostol was deduced from the fact that oral absorption is more rapid and possibly more predictable, with a peak serum concentration after oral administration of 34 minutes and a half-life of 20 - 40 minutes [7].

Uterine rupture in cases without uterine scarring or history of caesarian section is a rare, but potentially catastrophic complication in pregnancy and labor. Although misoprostol is commonly used in labor induction, research and reporting into its risks are limited due to the fact that it is not a registered drug for labor induction in most countries. We report a case of uterine rupture in an unscarred uterus following misoprostol induction to draw awareness to the need for extreme vigilance to complications arising from misoprostol-induced labor, such as post-partum hemorrhage.

\section{Case}

A 35-year-old-woman who had two previous uncomplicated vaginal deliveries and no medical history presented to our outpatient department due to post-date pregnancy at $40+3$ weeks. There was no abnormal finding on ultrasonogram of prenatal examination. Fetal monitor revealed irregular uterine contraction and fetal heart beat of 120 - 150 beats/min. Vaginal examination showed $1 \mathrm{~cm}$ cervical dilation, 20\% effacement, medium consistency, and middle position (Bishop Score: 4). She was admitted to our labor-delivery-recovery (LDR) room for further management and labor induction. During the course of labor, the patient was given oral misoprostol with titrated dosage, $20 \mu \mathrm{g}$ per hour for 4 doses beginning at 8:30 am and $40 \mu \mathrm{g}$ per hour for 5 doses from 12:30 pm. At 5:10 pm, the patient made a smooth vaginal delivery of a $3450 \mathrm{~g}$ male baby. However, at 6:50 pm, despite administration of oxytocin (3 amp IV), misoprostol (200 $\mu \mathrm{g} / \mathrm{tab} 2 \# \mathrm{SL}$ ) and transamine (250 g IV), the patient continued to display heavy blood loss totaling $1000 \mathrm{ml}$, while blood pressure dropped to 79/52 $\mathrm{mmHg}$ and heart rate increased to 117/min. Abdominal ultrasonography indicated severe intraabdominal bleeding. Under the impression of post-partum hemorrhage due to uterine blood vessel rupture, the patient was prepared for blood transfusion and emergency surgery. During the surgery, a congenital weak point on the left side of the posterior uterine wall with a ruptured hole and bleeder were discovered, thus necessitating emergency repair of ruptured hole. Because the persisting vaginal bleeding was noted post suture, the full hysterectomy was then performed. The specimen of ruptured uterus was shown in Figure 1. The perioperative blood loss was $8000 \mathrm{ml}$. Following surgery, the patient was transferred to the intensive-care-unit (ICU) for two days. After the patient's condition stabilized, she was then transferred to the maternity ward for an additional four days, at which point she had made a full recovery and was discharged. The follow-up of this patient was conducted at outpatient department.

\section{Discussion}

Uterine rupture is a rare and often serious complication of childbirth that involves a high incidence of fetal and maternal morbidity. Uterine rupture occurs following a breach of the myometrial wall, which often results in clinically significant uterine bleeding, spilling of uterine contents into the abdominal cavity, need for emergency

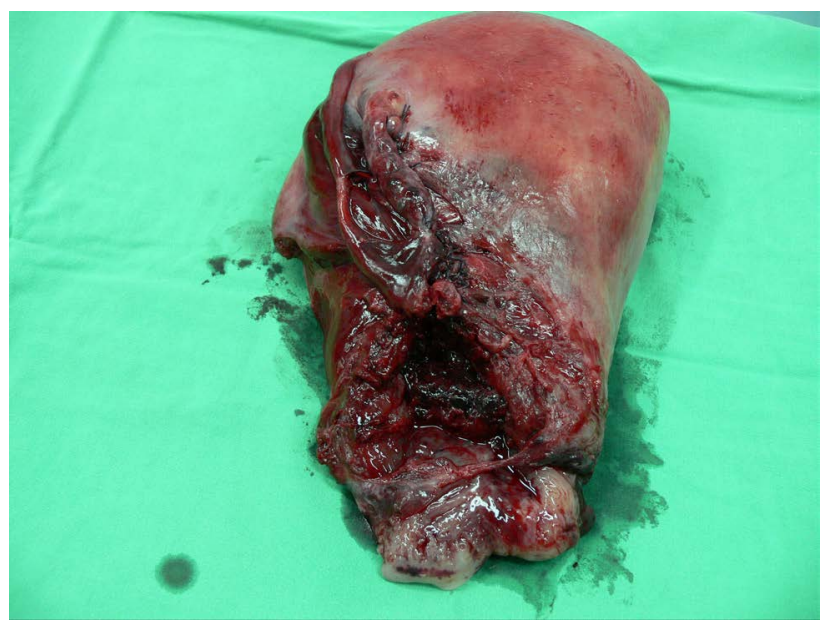

Figure 1. Photograph of ruptured uterus. 
caesarean section or hysterectomy. The most common risk factors for uterine rupture are the existence of a uterine scar, congenital uterine anomalies, multiparity, and labor induction. In this particular case, the patient's only significant risk factor was labor induction.

Misoprostol, a synthetic prostaglandin E1 analog originally approved for the prevention and treatment of gastrointestinal ulcers, is now widely used as an effective drug in labor induction. Misoprostol produces cervical ripening, effacement and uterine contractility and is relatively inexpensive and stable at room temperature [8] [9]. The major contraindications for the use of misoprostol in labor induction are previous uterine surgery (caesarean section, uterine myomectomy) and multiparity ( $>4)$, both of which increase risk of uterine rupture or dehiscence. In non-contraindicated cases, misoprostol is widely considered a safe and effective drug for labor induction, however because global use of misoprostol in labor induction is predominantly off-label, there is currently insufficient statistical understanding of the frequency and severity of risks [10] [11].

Emergency surgery revealed the patient's uterine rupture was due in part to a congenital weakness of the uterine wall. Uterine wall weakness (thin uterine wall) is known to be able to induce uterine rupture. Uterine wall weakness may be congenital or may develop as a result of uterine sacculation or uterine diverticulum occurring during pregnancy, thereby increasing the difficulty of diagnosis [12] [13]. Importantly, this condition can occur in primagravida patients who may otherwise be classified as low-risk in a misoprostol induction screening [14]. Future research should focus on evaluating the potential risk of uterine rupture in patients with uterine wall weakness undergoing misoprostol induction.

In this particular case, the patient had had only two previous vaginal births and had no history of uterine surgery, meaning she was at low risk for complications according to current clinical understanding. However, despite the lack of contraindicating factors, the patient suffered from a severe and life-threatening uterine rupture. Only through the extreme vigilance of the hospital staff and the quick implementation of emergency repair surgery or abdominal hysterectomy with transfusion was the patient able to make a full recovery. Thus, this case reflects the need for further clinical and experimental investigation into the risk-factors associated with misoprostol-induced labor and serves as a reminder to all physicians to practice extreme vigilance and caution when using this drug.

\section{Conclusion}

Despite no contraindication for labor induction with titrated oral misoprostol, it should keep in mind the risk of uterine rupture when practicing vaginal delivery.

\section{Acknowledgements}

We thank nurse practitioner Jo-Chen Tsai, anesthesiologist Hsiang-Ning Luk and his team members, and the staff of LDR room and ICU of China Medical University Beigang Hospital for their valuable assistance in this case.

\section{Conflicts of Interest}

The authors have no conflicts of interest relevant to this article.

\section{References}

[1] Thaisomboon, A., Russameecharoen, K., Wanitpongpan, P., Phattanachindakun, B. and Changnoi, A. (2012) Comparison of the Efficacy and Safety of Titrated Oral Misoprostol and a Conventional Oral Regimen for Cervical Ripening and Labor Induction. International Journal of Gynecology \& Obstetrics, 116, 13-16. http://dx.doi.org/10.1016/j.ijgo.2011.07.027

[2] McMaster, K., Sanchez-Ramos, L. and Kaunitz, A.M. (2015) Balancing the Efficacy and Safety of Misoprostol: A Meta-Analysis Comparing 25 versus 50 Micrograms of Intravaginal Misoprostol for the Induction of Labour. BJOG, 122, 468-476. http://dx.doi.org/10.1111/1471-0528.12935

[3] Cheng, S.Y. and Chen, T.C. (2006) Pilot Study of Labor Induction with Titrated Oral Misoprostol. Taiwanese Journal of Obstetrics and Gynecology, 45, 225-229. http://dx.doi.org/10.1016/S1028-4559(09)60229-1

[4] Cheng, S.Y., Ming, H. and Lee, J.C. (2008) Titrated Oral Compared with Vaginal Misoprostol for Labor Induction: A Randomized Controlled Trial. Obstetrics \& Gynecology, 111, 119-125. 
http://dx.doi.org/10.1097/01.AOG.0000297313.68644.71

[5] Ho, M., Cheng, S.Y. and Li, T.C. (2010) Titrated Oral Misoprostol Solution Compared with Intravenous Oxytocin for Labor Augmentation: A Randomized Controlled Trial. Obstetrics \& Gynecology, 116, 612-618. http://dx.doi.org/10.1097/AOG.0b013e3181ed36cc

[6] Cheng, S.Y., Hsue, C.S., Hwang, G.H., Chen, W. and Li, T.C. (2010) Comparison of Labor Induction with Titrated Oral Misoprostol Solution between Nulliparous and Multiparous Women. Journal of Obstetrics and Gynaecology Research, 36, 72-78. http://dx.doi.org/10.1111/j.1447-0756.2009.01118.x

[7] Zieman, M., Fong, S.K., Benowitz, N.L., Banskter, D. and Darney, P.D. (1997) Absorption Kinetics of Misoprostol with Oral or Vaginal Administration. Obstetrics \& Gynecology, 90, 88-92. http://dx.doi.org/10.1016/S0029-7844(97)00111-7

[8] Barrilleaux, P.S., Bofill, J.A., Terrone, D.A., Magann, E.F., May, W.L. and Morrison, J.C. (2002) Cervical Ripening and Induction of Labor with Misoprostol, Dinoprostone Gel, and a Foley Catheter: A Randomized Trial of 3 Techniques. American Journal of Obstetrics \& Gynecology, 186, 1124-1129. http://dx.doi.org/10.1067/mob.2002.123821

[9] Tang, O.S., Gemzell-Danielsson, K. and Ho, P.C. (2007) Misoprostol: Pharmacokinetic Profiles, Effects on the Uterus and Side-Effects. International Journal of Gynecology \& Obstetrics, 99, S160-S167. http://dx.doi.org/10.1016/j.ijgo.2007.09.004

[10] Voigt, F., Goecke, T.W., Najjari, L., Pecks, U., Maass, N. and Rath, W. (2015) Off-Label Use of Misoprostol for Labor Induction in Germany: A National Survey. European Journal of Obstetrics \& Gynecology and Reproductive Biology, 187, 85-89. http://dx.doi.org/10.1016/j.ejogrb.2014.11.026

[11] Hofmeyr, G.J., Gulmezoglu, A.M. and Pileggi, C. (2010) Vaginal Misoprostol for Cervical Ripening and Induction of Labour. Cochrane Database of Systematic Reviews, 2010, Article ID: CD000941. http://dx.doi.org/10.1002/14651858.cd000941.pub2

[12] Frei, K.A., Duwe, D.G., Bonel, H.M., Durig, P. and Schneider, H. (2005) Posterior Sacculation of the Uterus in a Patient Presenting with Flank Pain at 29 Weeks of Gestation. Obstetrics \& Gynecology, 105, 639-641. http://dx.doi.org/10.1097/01.AOG.0000141695.83741.94

[13] Rajiah, P., Eastwood, K.L., Gunn, M.L. and Dighe, M. (2009) Uterine Diverticulum. Obstetrics \& Gynecology, 113, 525-527. http://dx.doi.org/10.1097/AOG.0b013e31818da0b9

[14] Matsubara, S., Shimada, K., Kuwata, T., Usui, R. and Suzuki, M. (2011) Thin Anterior Uterine Wall with Incomplete Uterine Rupture in a Primigravida Detected by Palpation and Ultrasound: A Case Report. Journal of Medical Case Reports, 5, 14. http://dx.doi.org/10.1186/1752-1947-5-14 